\title{
The importance of the different kinds of energy sources for energy future of Turkey
}

\author{
Yusuf Alper Kaplan ${ }^{a}$, Canan Aladăg \\ Osmaniye Korkut Ata University, Energy System Department, Turkey
}

\begin{abstract}
Nowadays, the need of energy has been increasing day by day with the population growth and the advancements of technology. In this study, the current state of nuclear, wind and solar energy on the worldwide has been generally investigated. The general assessments have been made based on Turkey's energy potential and the evaluation situation of this potential. The current political structures of countries are generally assessed and under this policy, the last situation and the latest implemented innovations are given. Turkey's energy demand is constantly increasing and Turkey is a country that needs to energy imports. This is a need for new energy sources to meet the growing need for energy. Nuclear, wind and solar energy are the new sources of energy to the fore in our country recently. In this study is given general information on the usage of energy sources of making and some deficiencies were been emphasized by political considerations in this regard.
\end{abstract}

\section{Introduction}

Energy sources gain in importance at a fast pace from the aspect of both, the energy requirements of the country and more so, environment. This work that aims to give, the status of the energy potential in Turkey and the current energy structures of Turkey's policy. Turkey has high potential in terms of many energy sources. Fig. 1 shows that Turkey's installed capacity reached to 73,854.6 MW level at the end of February 2016.

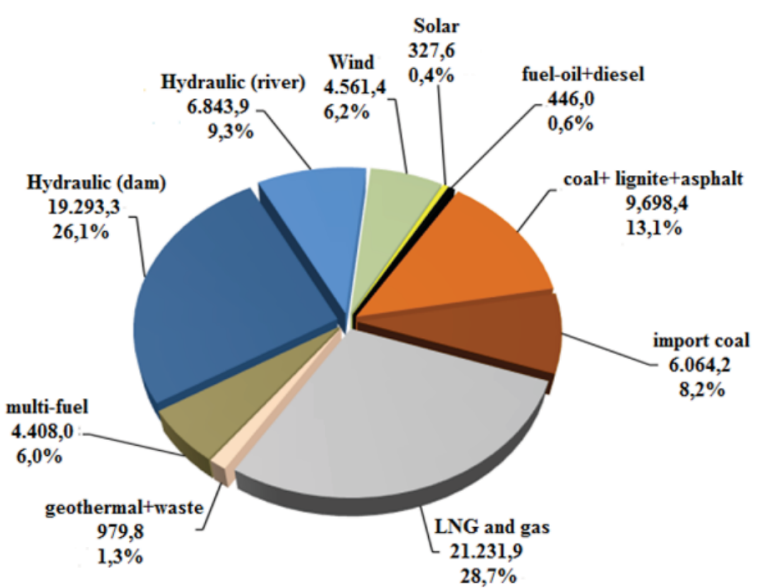

Fig. 1. Electric power installed capacity in Turkey (end of February 2016) [1]

The most important technique is to increase the diversity of energy sources to ensure energy security for the country. As it can be understood from the graph, use of nuclear energy does not have in Turkey. Significant investments are made in our country about nuclear, wind and solar energy sources and support policies to increase the use of them has been developed.

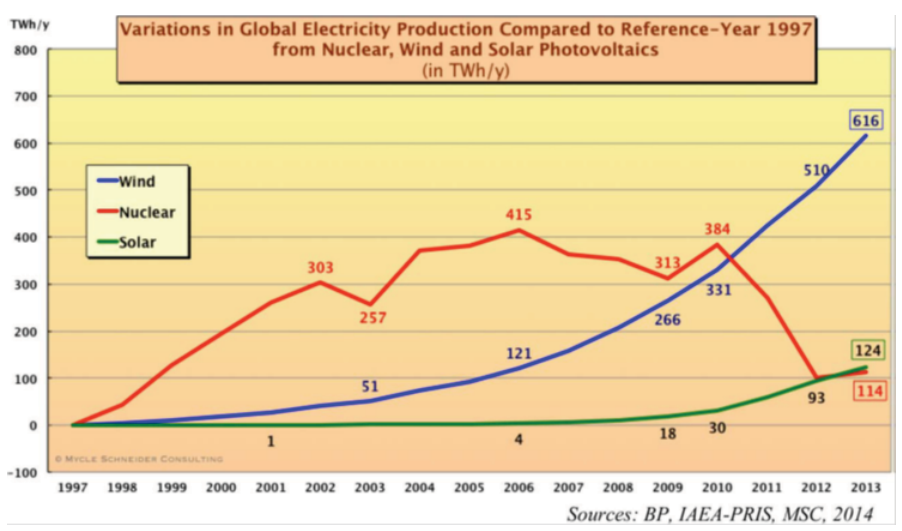

Fig. 2. Variation in Global Electricity Production from Nuclear, Wind and Solar [2]

Fig. 2 presents the actual electricity produced by solar photovoltaics, wind and nuclear power and highlights the changing levels of production since 1997[3].

\section{Wind Energy}

The importance of the using of renewable energy resources are realized while considering the limited duration of the use of fossil fuel resources. Wind energy sector has shown a rapid development all over the world in recent years. As a result of the last technological improvements, popular support mechanism and new incentives, the share in wind energy of power production has continuously increased.

\footnotetext{
$\bar{a}$ Corresponding author: yakaplan@osmaniye.edu.tr
} 


\subsection{The General State of Wind Energy in the World}

The using of the wind energy varies temporally and geographically. The installed wind power capacity which is from 2004 to 2014 in the world is shown in Fig. 1. The total installed wind power capacity of the world was $238,050 \mathrm{GW}$ with more than $20 \%$ growth rate in the annual market at the end of 2012. The wind power capacity in 2013 reached to $318,137 \mathrm{GW}$ level with an increase of about $80 \mathrm{GW}$. At the end of 2014, the installed total wind power capacity reached $369,553 \mathrm{GW}$ in the world [4].

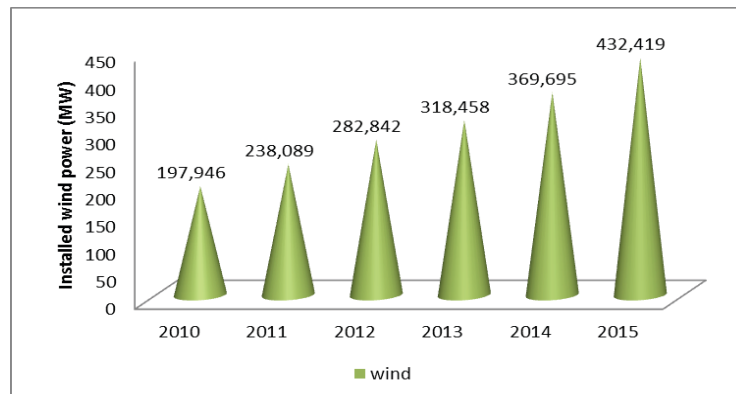

Fig. 3. Installed wind power capacity in the world [5]

\subsection{The General State of Wind Energy in Turkey}

Turkey is one of the richest countries in terms of wind power potential depending on its location. It is clearly seen in Fig. 4 that the installed wind energy capacity of Turkey seems to be very noticeable. It can be said that the total installed wind power capacity began to increase more rapidly last five years. The installed wind power capacity of Turkey is shown in Fig. 4 year by year. In 2012, wind power capacity is increased with $531 \mathrm{MW}$ and total installed wind power capacity reached to 2260.5 MW level. In 2013, 499.1 MW of new wind power installed and total installed wind power reached 2759.6 MW level. Turkey added 58.2 MW of new wind power in 2015 for a total capacity of $4561.4 \mathrm{MW}$. It can be said that based on the Fig. 4 Turkey's total installed capacity has nearly $\% 30$ growth rate per year since 2011 and total installed wind power of Turkey 4561.4 MW in 2016.

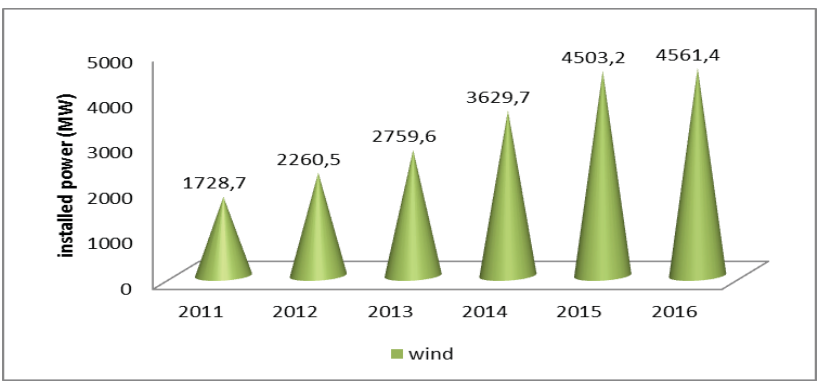

Fig. 4. Installed wind energy capacity in the Turkey

\section{Solar Energy}

Recently, the need of the using of energy has been increasing continuously with the improvements of technology and growth of the population for all countries. The prices of energy consumption in a country greatly affect its economy. In this case, the using of the renewable energy sources is a substantial research topic in the worldwide and its technology and investments improve progressively. Especially, EU countries are the pioneer of using renewable energy source instead of using fossil fuels [7]. Solar energy contributes diversification to using of the energy sources and this ensures the security of energy supplies. It also allows reclamation of degraded land and electrification of rural and remote communities [8].

\subsection{Solar Energy in the World}

The total installed solar energy capacity of the world from 2010 to 2014 is shown in Fig. 5. It is seen in the Fig. 5 that the world's total installed solar power capacity was $100 \mathrm{GW}$ with more than $40 \%$ growth rate in the annual market at the end of 2012. The world's total installed solar energy capacity reached to approximately $138 \mathrm{GW}$ at the end of 2013. This capacity is capable of generating as much annual electrical energy as 16 coal power plants. These PV installations save more than 53 million tons of $\mathrm{CO}_{2}$ each year $[9,10]$. Nearly $39 \mathrm{GW}$ of new solar power capacity was installed around the world in 2014 , so the total installed capacity reach to $177 \mathrm{GW}$ [9].

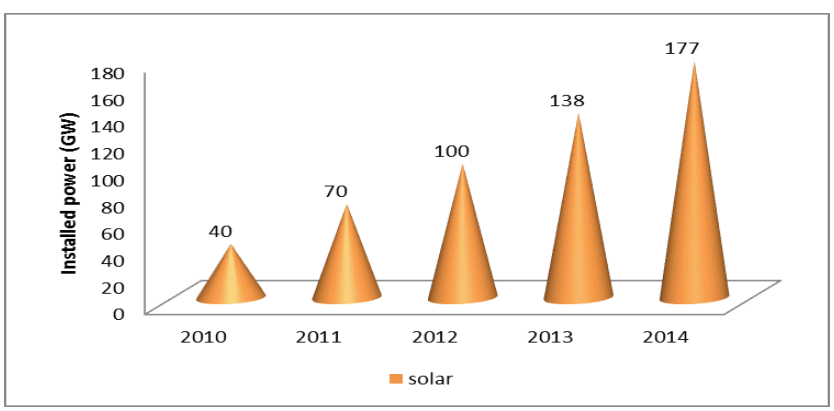

Fig. 5. Installed Solar Power Capacity in the World [11]

\subsection{Solar Energy in Turkey}

Turkey situated latitudes $36^{\circ}$ and $42^{\circ}$ north and due to its geographic position it is a fortunate country from the aspect of possessing a vast potential in solar energy, compared to quite a number of countries.

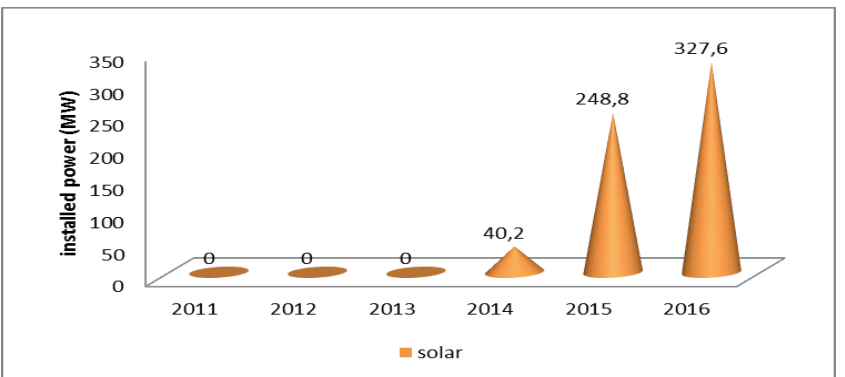

Fig. 6. Installed solar energy capacity in the Turkey [12] 
The installed solar power in Turkey is shown in Fig. 6 year by year from 2011 until 2016. When you consider the potential of solar energy in Turkey, the result seems to be very dramatic. Turkey's solar energy potential have been identified that annual sunshine duration of Turkey is very remarkable but, it is clearly seen that the installed solar energy of Turkey begins from 2014. Installed solar power showed a significant increase from 2014 to today with 287.4 MW. Complicated and slow administrative procedures are the greatest obstacle for solar energy development in previous period in Turkey. The Turkish Solar Energy capacity has set a target of reaching $5 \mathrm{GW}$ in 2023 [4]. There are some solar energy projects in Turkey such as "3000 MW Solar Farm Project" which will be constructed in Konya.

\section{Nuclear energy}

Nuclear is obtained as a result of reactions occurring in the core of the atom. With the implementation of an alternative energy development strategy, urgent strides are necessary to find sources of alternative energy. The generation of electricity from nuclear power plants with their lower-cost, greenhouse-gas-free clean energy and solid security should be an alternative in the world [13].

\subsection{Nuclear Energy in the World}

Nuclear energy is a mature low greenhouse gas emission source of base load power, but its share of global electricity generation has been declining for the past twenty years. While nuclear power could make an increasing contribution to low carbon energy supply, a variety of barriers and risks exist including operational risks, and associated concerns like the environmental impact of uranium mining, financial and regulatory risks, unresolved waste management issues, nuclear weapons proliferation concerns, and adverse public opinion [3].

But, nuclear energy have a big capacity in the energy of the world the nuclear energy reactor and power capacity of some countries are given Fig. 7 .

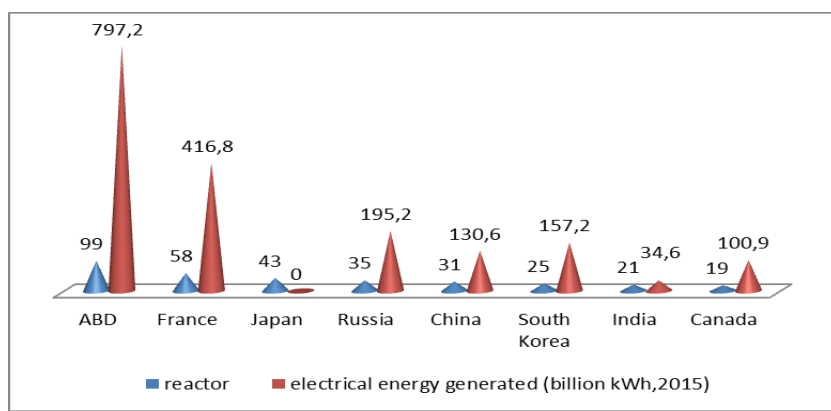

Fig. 7. Nuclear energy power and reactors for some countries [2]

\subsection{Nuclear Energy in Turkey}

Turkey, geographically deprived of natural resources, generate almost all of its electricity through imported energy sources such as natural gas and oil. To date, most of the electricity is generated through natural gas while the remaining is almost fully generated through oil. However, with the increasing concern about price volatility, rising electricity demand and energy security, Turkey is considering tapping into the field of nuclear energy to generate electricity. Nuclear energy, being a clean energy, also contributes toward environment sustainability by reducing the amount of carbon dioxide emitted into the atmosphere [14]. Nuclear power is often hailed as a technology which is important for mitigating climate change while providing energy necessary for economic development. Turkey is one of ten nuclear Newcomers which has most of the basic capacities and motivations historically observed in countries introducing nuclear energy: a large economy, an adequate electricity grid, and rapidly-growing electricity demand combined with energy dependence concerns. The Turkish state has always had a strong motivation for nuclear power. Since 1960 electricity consumption in Turkey grew on average $9 \%$ per year as compared to $7 \%$ for the world as a whole [15]. As a country poor in fossil resources, Turkey has been increasingly dependent on imported energy to meet its electricity needs and in recent decade energy security was cited as one of the main reasons for pursuing nuclear power. The establishment of planned nuclear power plants in Turkey are given in Fig. 8.

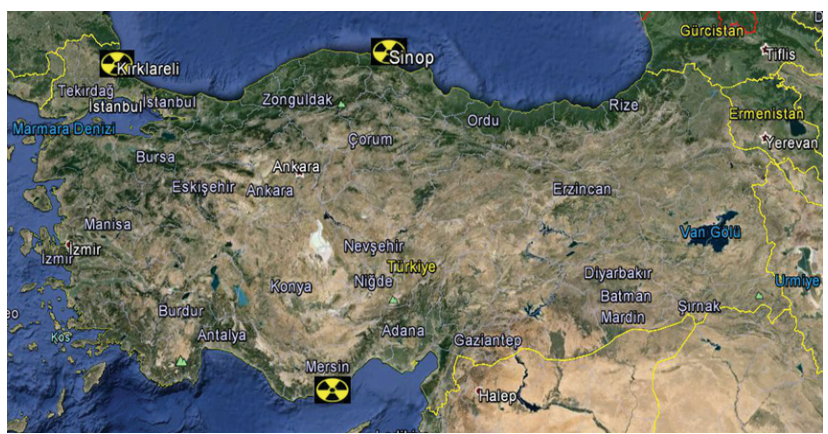

Fig. 8. The nuclear reactors are planned to be established in Turkey

In order to meet the fast rising demand for electricity, and reduce the risks associated with being dependent on imports, it is planned to take 2 nuclear power plants into operation by 2023 , and to begin the construction of a further 3 during the same period. With this purpose in mind, the company, Akkuyu Nuclear Power Plant Electricity Generation, which was established within the framework of the agreement between the Republic of Turkey and the Russian Federation, which took effect on 27 December 2010, for the establishment of a nuclear power plant in the Mersin. Together with this agreement, it is envisaged that a nuclear plant comprising four VVER-1200 type units, and with a total installed capacity of 4.800 MW. On the other hand, an agreement was also signed in 2013, for the establishment of a nuclear plant in Sinop, and the work related to this is currently ongoing. That the power plant is expected to be $4480 \mathrm{MW}$ [16].

Turkey Atomic Energy Agency (TAEK) according to the information received from the central resource for third-İgneada Kirklareli region forward as an alternative to leaving the focus on the Düzce-Akcakoca is stated. 
Electricity transmission, distribution, due to advantages such as transportation voiced İğneada will be the first choice.

\section{Expectations of Energy Future of Turkey}

With a rapidly growing economy, Turkey has become one of the fastest growing energy markets in the world. Over the last decade, Turkey has been the second country, after China, in terms of natural gas and electricity demand increase. The limits of Turkey's domestic energy sources in light of its growing energy demand have resulted in dependency on energy imports, primarily of oil and gas. The primary aim of Turkey is to realize its own energy security. The fundamental objectives of energy policies in Turkey as followings:

$>$ diversify its energy supply routes and source countries,

$>$ increase the share of renewables and include the nuclear in its energy mix,

$>$ take significant steps to increase energy efficiency,

$>$ contribute to Europe's energy security.

In our country, to meet the increasing energy demand, to reduce dependence on foreign energy and environmental, energy production due to the positive impact of the decision was made to benefit from nuclear energy [17].

\section{Conclusion}

The current situation of nuclear, wind and solar energy in Turkey and the worldwide are generally evaluated by using recent data. This article also assessed the political structure of Turkey by looking at the installed wind and solar energy power. Turkey has rich wind and solar energy potential, which may be used for electricity power generation provided the necessary political and technological steps are taken. The rapid growth in renewable energy system installation due to the increase in energy demand had led to a growing demand for better politic structure as well as modelling. The most important deficiencies are determined and some proposals are presented in order to increase the using of renewable energy sources. Based on the supply and demand projections for electricity energy in our country, it is aimed that the share of the electricity generated by nuclear energy plants within the total, reach $5 \%$ by 2025 .

The nuclear energy will be one of the most important energy source in the future for Turkey. Consequently, it is necessary to seriously studies on nuclear energy subject. Furthermore, universities should put more emphasis on high level education and training in the area of renewable energy.

\section{References}

1. www.teias.gov.tr

2. www.iaea.org Power Reactor Information System, (2016)

3. Nuclear Power Versus Renewable Energy-Trend Analysis, Vol. 103, No. 4, Proceedings of the IEEE, April (2015)

4. GWEC (Global Wind Energy Council), Global wind 2014 report, March, (2015)

5. www.ewea.org

6. www.tureb.com.tr

7. Y.A. Kaplan and I. San, Green Energy ConferenceVI (IGEC-VI), Eskisehir, Turkey, (2011)

8. K.H. Solangi, et al., Renew Sustain Energy Rev, 15: 2149-63, (2011)

9. Renewable 2014 Global Status Report, REN21, (2013)

10. European Photovoltaic Industry Association (EPIA), Global Market Outlook For Photovoltaics 20132017, (2013)

11. D. Bahrehmand, M. Ameri, Renewable Energy 74, 357-368, 2015

12. http://dektmk.org.tr

13. A review on nuclear power plant scenario in Thailand, Parinya Pongsoi a, Somchai Wongwises, Renewable and Sustainable Energy, 586-592 (2013)

14. C.E. Seng, L.C. Kiat, The System Dynamics of Nuclear Energy for Singapore, IGEC-6, 5-9 June, (2011)

15. H.A. Simsek, N. Simsek, Recent incentives for renewable energy in Turkey, Energy Policy, 63, 521530, (2013)

16. http://enerji.gov.tr

17. www.mfa.gov.tr 